\title{
Report on Ghosting in LL94 RAR Data
}

\author{
S. K. Lehman
}
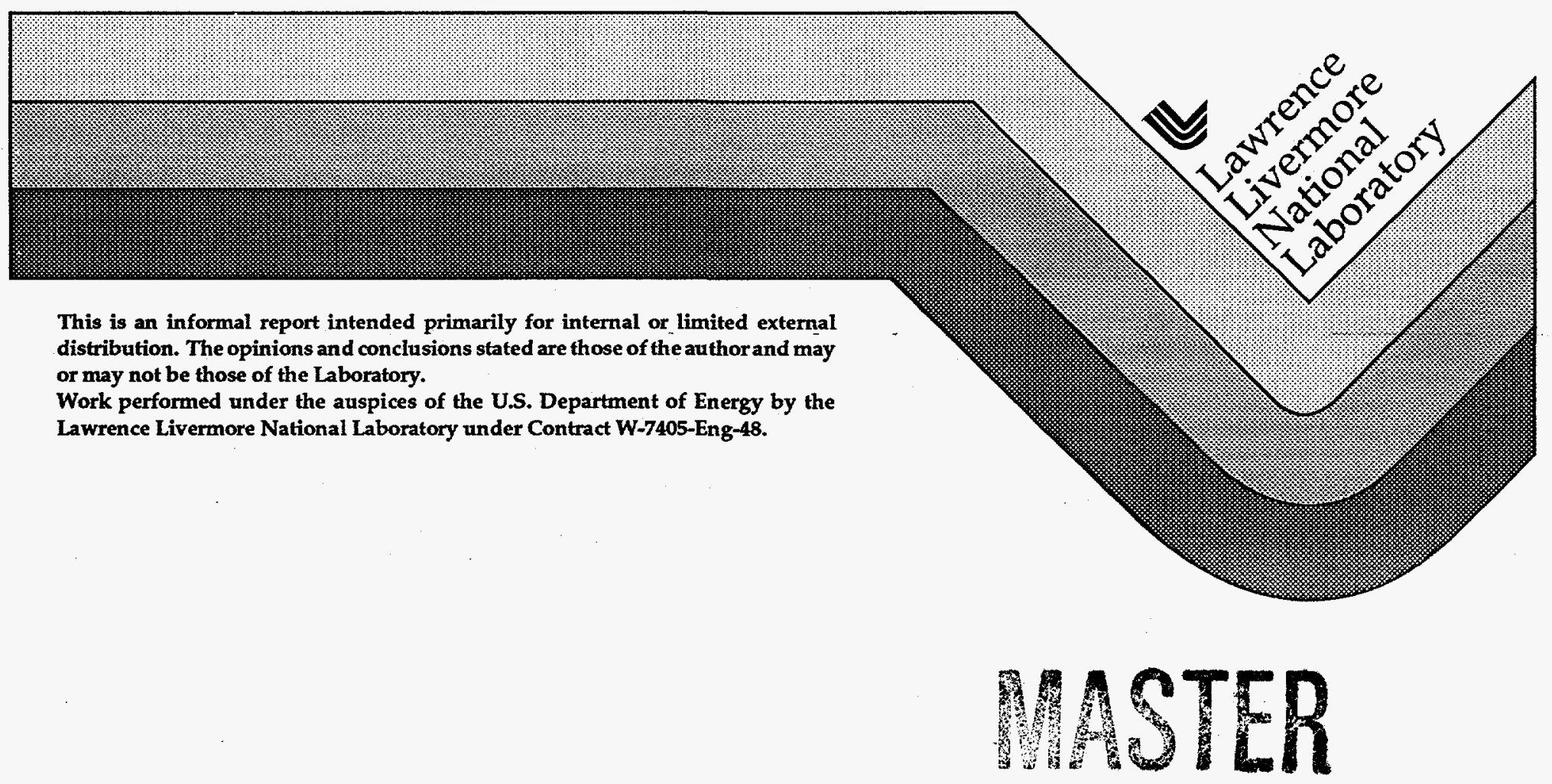


\section{DISCLAIMER}

This document was prepared as an account of work sponsored by an agency of the United States Government. Neither the United States Government nor the University of California nor any of their employees, makes any warranty, express or implied, or assumes any legal liability or responsibility for the accuracy, completeness, or usefulness of any information, apparatus, product, or process disclosed, or represents that its use would not infringe privately owned rights. Reference herein to any specific commercial product, process, or service by trade name, trademark, manufacturer, or otherwise, does not necessarily constitute or imply its endorsement, recommendation, or favoring by the United States Government or the University of California. The views and opinions of authors expressed herein do not necessarily state or reflect those of the United States Government or the University of California, and shall not be used for advertising or product endorsement purposes.

This report has been reproduced directly from the best available copy.

Available to DOE and DOE contractors from the Office of Scientific and Technical Information P.O. Box 62, Oak Ridge, TN 37831

Prices available from (615) 576-8401, FTS 626-8401

Available to the public from the National Technical Information Service

U.S. Department of Commerce 5285 Port Royal Rd. Springfield, VA 22161 


\section{DISCLAMMER}

Portions of this document may be illegible in electronic image products. Images are produced from the best available original document. 


\title{
Report on Ghosting in LL94 RAR Data
}

\author{
S. K. Lehman \\ University of California \\ Lawrence Livermore National Laboratory \\ Livermore, CA 94550
}

January 22, 1996

\section{Introduction}

Ghosting in the Loch Linnhe 1994 (LL94) real aperture radar (RAR) data is the phenomenon of two range cells with high returns separated by two range cells with lower returns.

The occurrence of ghosting is sporadic, there appears to be no relation between the value of the high returns, and there appears to be no relation between ghosting in the I (real) and Q (imaginary) parts of a range line. It was believed ghosting was due to a byte shift in the data. It only appears in data processed with the Livermore RAR codes.

Figure 1 shows an example of ghosting taken from the Priority 1 LL94 image (September 14, 1994, Run 1, 13:36:57).

We present the steps used in diagnosing the problem, the eventual determination of the cause, and the solution.

\section{Discussion}

The LL94 RAR data in its "raw" form can be view as a sequence of data planes, each consisting three blocks (header, return data, and parity) arranged sequentially as follows:

\begin{tabular}{|l|r|}
\hline Header & 128 bytes \\
Data & 4096 bytes \\
Parity & 2 bytes \\
\hline Total & 4226 bytes \\
\hline
\end{tabular}

It was originally believed the ghosting was a result of a byte shift in a plane, most likely occurring between the end of the header and the beginning of the data. Figure 2 shows the arrangement of four sequential data planes when the radar is operating in monostatic band and polarization agile mode.

The LLNL RAR codes read and process one plane at a time. The data plane, as implemented in the C codes, is a structure:

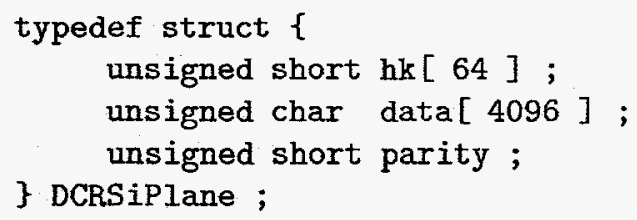

We verified using the $C$ function call sizeof (DCRSiPlane) that this structure is indeed 4226 bytes, i.e. the compiler does not add any padding to it.

For the purposes of studying the problem, we define a -1 shift of the data as subtraction of one byte off the header or a left shift of the data block; $a+1$ shift is the addition of one byte to the header or a right 
shift of the data. These are equivalent to making the header 127 bytes long and 129 bytes long respectively. Similar definitions hold for \pm 2 shifts.

Extensive "debugging" of the codes revealed no sources of shifts. We believe shifts could be introduced at two points in the processing:

- During the read from disk;

- During the extraction of range data from the data plane.

We induced shifts at each of these steps. Shifts during the read result in a loss of synchronization (i.e. a loss of the 0x5555 and OxAAAA synchronization bytes) each time a plane is read. The consequence is a loss of every other data plane (hence half the entire data set) while the code re-synchronizes itself. Since this does not occur without the induced shift, we concluded there were no shifts induced during a read.

\pm 1 shifts induced during the extraction of the range data result in the elimination of the ghosting. However, we can introduce different ghosts by \pm 2 shifts. The induced \pm 1 shifts eliminate the ghosting without other obvious changes in the intensity or Doppler spectra images. The result of these shifts on the range line presented in Figure 1 are shown in Figures 3 and 4. The Doppler profiles are shown in Figure 5.

By comparing, byte-by-byte, the shifted data to data obtained from the British Defense Research Agency (DRA), we still found differences in the data and ruled out the possibility of shifts in the data plane with respect to the header.

The effect of such shifts on a single range line are demonstrated in the following table. co represents a copolarized return, while $x$ represents a cross-polarized term. Each column represents the real and imaginary parts of a range line as would be extracted from the data plane after the specified shift.

\begin{tabular}{|c|c|c|c|c|}
\hline-2 Shift & -1 Shift & 0 Shift & +1 Shift & +2 Shift \\
\hline (garbage,co I 1) & (garbage,co I 2) & $(\operatorname{col} 1, \cos 1)$ & $(\operatorname{co~I~2,co~Q~2)~}$ & $(\cos \mathrm{Q} 1, \times \mathrm{I} 1)$ \\
\hline (garbage,co I 2 ) & $(\operatorname{col} 1, \operatorname{co} Q 1)$ & $(\operatorname{co~I~2,co~Q~2)~}$ & $(\operatorname{co~Q~} 1, \times I 1)$ & $(\operatorname{co~Q~} 2, x$ I 2$)$ \\
\hline$(x$ Q 1, co I 3$)$ & $(x Q 2, \operatorname{co~I~4)~}$ & $(\operatorname{co~I~3,co~Q~3)~}$ & $(\operatorname{coI} 4, \operatorname{co} Q 4)$ & $(\operatorname{co~Q~3,x~I~3)~}$ \\
\hline$(\times Q 2, \operatorname{coI} 4)$ & $(\operatorname{co~I~} 3, \operatorname{co} Q 3)$ & $(\operatorname{coI} 4, \operatorname{co} Q 4)$ & $(\operatorname{co~Q~} 3, x$ I 3) & $(\operatorname{co~Q~4,x~I~4)~}$ \\
\hline$(x Q 3$, co I 5) & $(\times Q 4$, co I 6) & $(\operatorname{coI} 5, \operatorname{co} Q 5)$ & $(\operatorname{co~I~6,co~Q~6)~}$ & (co Q 5,x I 5) \\
\hline$(\times Q 4, c 0$ I 6$)$ & $(\operatorname{co~I~} 5, \operatorname{co} Q 5)$ & $(\operatorname{coI} 6, \operatorname{co} Q 6)$ & $(\operatorname{co~Q~5,x~I~5)~}$ & $(\operatorname{co} Q 6, \times$ I 6) \\
\hline$\vdots$ & & & & \\
\hline ( $\times$ Q N-5,co I N-3) & (× Q N-4,co I N-2) & $(\operatorname{coI~N-3,co~Q~N-3)~}$ & (co I N-2,co Q N-2) & $(\operatorname{co} Q \mathrm{~N}-3, \times \mathrm{I} N-3)$ \\
\hline ( $x$ Q N-4, co I N-2) & $(\operatorname{co~I~N-3,co~Q~N-3)~}$ & $(\operatorname{coI} N-2, \operatorname{co} Q \mathrm{~N}-2)$ & (co Q N-3,x I N-3) & $(\operatorname{co} Q \mathrm{~N}-2, x \mathrm{I} N-2)$ \\
\hline ( $\times$ Q N-3, co I N-1) & $(\times \mathrm{Q} N-2, \operatorname{col} \mathrm{N})$ & $(\operatorname{coIN}-1, \operatorname{co} Q \mathrm{~N}-1)$ & $(\operatorname{coI} N, \operatorname{co} Q N)$ & $(c o Q N-1, \times I N-1)$ \\
\hline$(x Q \mathrm{~N}-2, \mathrm{co} I \mathrm{~N})$ & $(\operatorname{co~I~N-1,co~Q~N-1)~}$ & $(\operatorname{co~I~N,co~Q~N)~}$ & (co Q N-1,x I N-1) & $(\operatorname{co~Q~N,x~I~N)~}$ \\
\hline
\end{tabular}

We were unable to identify a pattern in the above returns which, when shifted, would alternatively induce and eliminate ghosts. However, when comparing the list of numbers from DRA with those processed with the LLNL codes, we discovered the numbers in each range cell were correct but the channels were swapped.

Thus, by swapping the data bytes (but not the header bytes), we were able to eliminate the ghosting. We verified the header bytes are not swapped. When they are, the header information becomes corrupted.

\section{Conclusions}

We have determined the cause of the ghosting in the LL94 data processed with the LLNL codes was due to the data bytes being swapped. The codes have been modified to swap the data bytes.

All LL94 data distributed to date by LLNL must be considered corrupted. We are in the process of re-processing the data for distribution. 


\section{PRF Count 10701657 with 0 Shift}
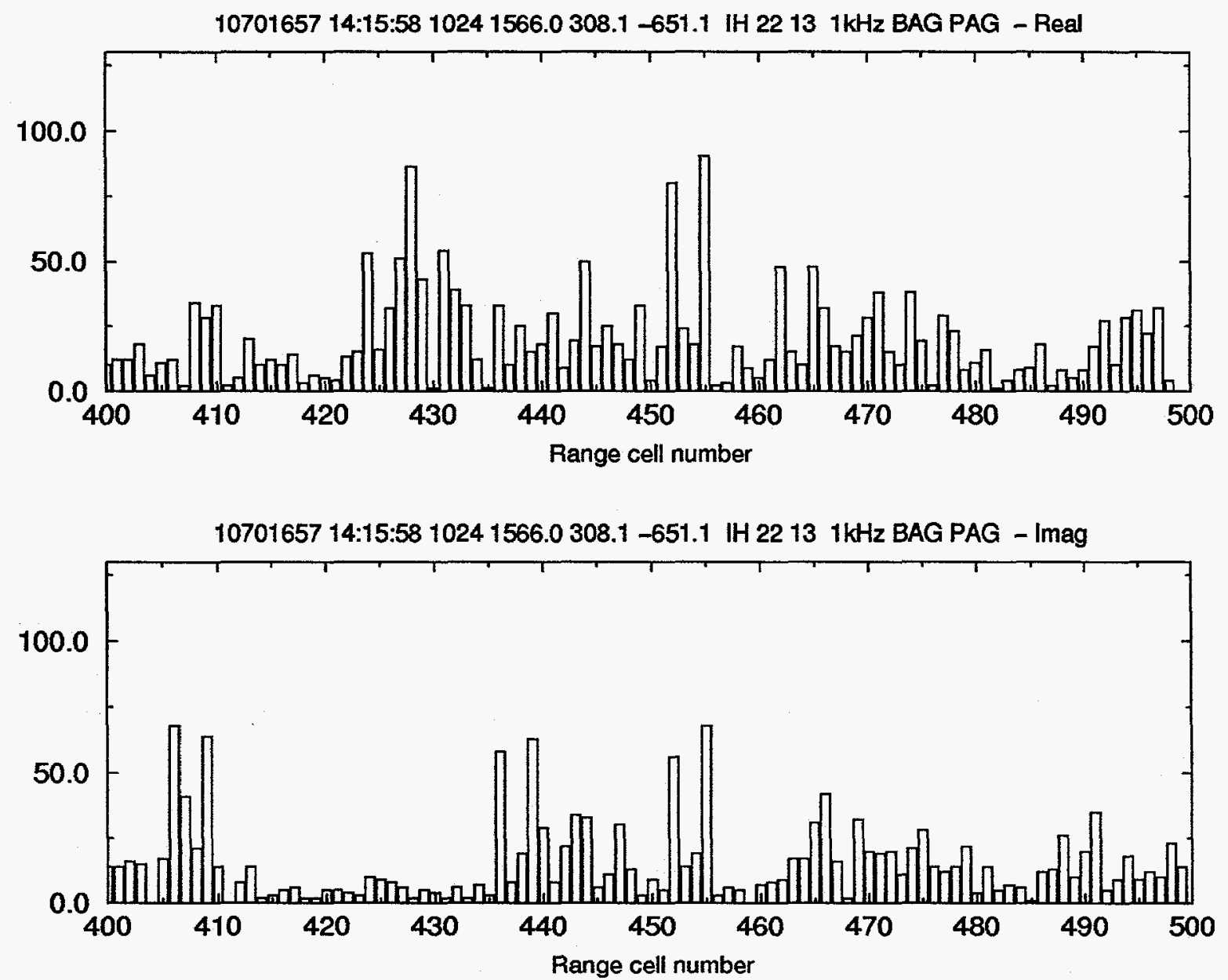

Figure 1: Ghosting example taken from LL94 Priority 1. The PRF count number is 10701657. Only range cells 400 to 500 out of 1024 are shown. One ghost appears between cells 450 and 460 in the real channel. There are three in the imaginary channel: Prior to range cell 410 , prior to 440 , and between 450 and 460 . 


\begin{tabular}{|c|c|c|c|c|c|c|c|c|c|c|c|c|c|c|}
\hline \multirow{2}{*}{$\begin{array}{l}\mathbf{h} \\
0 \\
\mathbf{u} \\
\mathbf{u} \\
\hat{\mathbf{k}} \\
\mathbf{k} \\
\mathbf{e} \\
\mathbf{e} \\
\mathbf{p} \\
\mathbf{1} \\
\mathbf{n} \\
\mathbf{g}\end{array}$} & $\begin{array}{l}\text { IVV } \\
1 \\
\text { cell } 1\end{array}$ & $\begin{array}{l}\text { IVV } \\
Q \\
\text { cell } 1\end{array}$ & $\begin{array}{c}\text { IVH } \\
\text { I } \\
\text { cell } 1\end{array}$ & $\begin{array}{c}\text { IVH } \\
Q \\
\text { cell } 1\end{array}$ & $\begin{array}{l}\text { IVV } \\
1 \\
\text { cell } 3\end{array}$ & $\begin{array}{c}\text { IVV } \\
Q \\
\text { cell } 3\end{array}$ & $\begin{array}{c}\text { IVH } \\
1 \\
\text { cell } 3\end{array}$ & $\begin{array}{c}\text { IVH } \\
Q \\
\text { cell } 3\end{array}$ & \multirow{2}{*}{$\bullet \bullet$} & $\begin{array}{c}\text { IVV } \\
1 \\
\text { cell N-1 }\end{array}$ & $\begin{array}{c}\text { IVV } \\
Q \\
\text { cell } N-1\end{array}$ & $\begin{array}{c}\text { IVH } \\
1 \\
\text { cell } N-1\end{array}$ & $\begin{array}{c}\text { IVH } \\
Q \\
\text { cell } N-1\end{array}$ & $p$ \\
\hline & $\begin{array}{c}\text { IVV } \\
1 \\
\text { cell } 2\end{array}$ & $\begin{array}{c}\text { IVV } \\
Q \\
\text { cell } 2\end{array}$ & $\begin{array}{c}\text { IVH } \\
\text { I } \\
\text { cell } 2\end{array}$ & $\begin{array}{c}\text { IVH } \\
Q \\
\text { cell } 2\end{array}$ & $\begin{array}{c}\text { IVV } \\
\text { I } \\
\text { cell } 4\end{array}$ & $\begin{array}{c}\text { IVV } \\
Q \\
\text { cell } 4\end{array}$ & $\begin{array}{c}\text { IVH } \\
\text { I } \\
\text { cell } 4\end{array}$ & $\begin{array}{c}\text { IVH } \\
Q \\
\text { cell } 4\end{array}$ & & $\begin{array}{c}\text { IVV } \\
\text { I } \\
\text { cell N }\end{array}$ & $\begin{array}{c}\text { IVV } \\
Q \\
\text { cell } N\end{array}$ & $\begin{array}{c}\text { IVH } \\
1 \\
\text { cell } N\end{array}$ & $\begin{array}{c}\text { IVH } \\
Q \\
\text { cell } N\end{array}$ & \\
\hline \multirow{2}{*}{$\begin{array}{l}\mathrm{h} \\
\mathrm{o} \\
\mathrm{u} \\
\mathrm{s} \\
\mathrm{e} \\
\mathbf{k} \\
\mathrm{e} \\
\mathbf{e} \\
\mathbf{p} \\
\mathbf{1} \\
\mathrm{n} \\
\mathrm{g}\end{array}$} & $\begin{array}{c}\mathrm{JHH} \\
1 \\
\text { cell } 1\end{array}$ & $\begin{array}{c}\mathrm{JHH} \\
\mathrm{Q} \\
\text { cell } 1\end{array}$ & $\begin{array}{c}\text { JHV } \\
\text { I } \\
\text { cell } 1\end{array}$ & $\begin{array}{c}\text { JVH } \\
Q \\
\text { cell } 1\end{array}$ & $\begin{array}{c}\mathrm{JHH} \\
1 \\
\text { cell } 3\end{array}$ & $\begin{array}{c}\mathrm{JHH} \\
\mathrm{Q} \\
\text { cell } 3\end{array}$ & $\begin{array}{c}\text { JHV } \\
1 \\
\text { cell } 3\end{array}$ & $\begin{array}{c}\text { JHV } \\
\mathbf{Q} \\
\text { cell } 3\end{array}$ & \multirow{2}{*}{$\bullet \bullet$} & $\begin{array}{c}\mathrm{JHH} \\
\quad 1 \\
\text { cell } \mathrm{N}-1\end{array}$ & $\begin{array}{c}\mathrm{JHH} \\
\mathrm{Q} \\
\text { cell } N-1\end{array}$ & $\begin{array}{c}\text { JHV } \\
I \\
\text { cell } N-1\end{array}$ & $\mid \begin{array}{c}J H V \\
Q \\
\text { cell } N-1\end{array}$ & $p$ \\
\hline & $\begin{array}{c}\mathrm{JHH} \\
I \\
\text { cell } 2\end{array}$ & $\begin{array}{c}\mathrm{JHH} \\
\mathrm{Q} \\
\text { cell } 2\end{array}$ & $\begin{array}{l}\text { JHV } \\
\text { I } \\
\text { cell } 2\end{array}$ & $\begin{array}{c}\text { JHV } \\
Q \\
\text { cell } 2\end{array}$ & $\begin{array}{c}\text { JHH } \\
1 \\
\text { cell } 4\end{array}$ & $\begin{array}{c}\text { JHH } \\
Q \\
\text { cell } 4\end{array}$ & $\begin{array}{c}\text { JHV } \\
\quad 1 \\
\text { cell } 4\end{array}$ & $\begin{array}{c}\mathrm{JHV} \\
\mathrm{Q} \\
\text { cell } 4\end{array}$ & & $\begin{array}{c}\mathrm{JHH} \\
1 \\
\text { cell } \mathrm{N}\end{array}$ & $\begin{array}{c}\mathrm{JHH} \\
\mathrm{Q} \\
\text { cell } \mathrm{N}\end{array}$ & $\begin{array}{c}\text { JHV } \\
\text { I } \\
\text { cell N }\end{array}$ & $\begin{array}{c}\mathrm{JHV} \\
\mathrm{Q} \\
\text { cell } \mathrm{N}\end{array}$ & $\begin{array}{l}1 \\
\text { y }\end{array}$ \\
\hline \multirow{2}{*}{$\begin{array}{l}\mathrm{h} \\
\mathrm{o} \\
\mathrm{u} \\
\mathbf{s} \\
\mathrm{e} \\
\mathrm{k} \\
\mathrm{e} \\
\mathrm{e} \\
\mathrm{p} \\
\mathbf{1} \\
\mathrm{n} \\
\mathrm{g}\end{array}$} & $\begin{array}{c}\text { IHH } \\
1 \\
\text { cell } 1\end{array}$ & $\begin{array}{c}\mathrm{IHH} \\
Q \\
\text { cell } 1\end{array}$ & $\begin{array}{c}\text { IHV } \\
1 \\
\text { cell } 1\end{array}$ & $\begin{array}{c}\text { IHV } \\
Q \\
\text { cell } 1\end{array}$ & $\begin{array}{c}\mathrm{IHH} \\
1 \\
\text { cell } 3\end{array}$ & $\begin{array}{c}\mathrm{IHH} \\
\mathrm{Q} \\
\text { cell } 3\end{array}$ & $\begin{array}{c}\text { IHV } \\
\text { I } \\
\text { cell } 3\end{array}$ & $\begin{array}{c}\text { IHV } \\
Q \\
\text { cell } 3\end{array}$ & \multirow{2}{*}{$\bullet \bullet \bullet$} & $\begin{array}{c}\mathrm{IHH} \\
\quad \\
\text { cell } \mathrm{N}-1\end{array}$ & $\begin{array}{c}\mathrm{IHH} \\
\mathbf{Q} \\
\text { cell } \mathrm{N}-1\end{array}$ & $\begin{array}{c}\mathrm{IHV} \\
1 \\
\text { cell } \mathrm{N}-1\end{array}$ & $\mid \begin{array}{c}\mathrm{IHV} \\
\mathbf{Q} \\
\mathrm{cell} N \mathrm{~N}-1\end{array}$ & $\begin{array}{l}p \\
a \\
r\end{array}$ \\
\hline & $\underset{1}{\mathrm{IHH}}$ & $\begin{array}{c}\mathrm{IHH} \\
\mathrm{Q} \\
\text { cell } 2\end{array}$ & $\begin{array}{c}\text { IHV } \\
1 \\
\text { cell } 2\end{array}$ & $\begin{array}{c}\mathrm{IHV} \\
\mathrm{Q} \\
\text { cell } 2\end{array}$ & $\begin{array}{c}\mathrm{IHH} \\
1 \\
\text { cell } 4\end{array}$ & $\begin{array}{c}\mathrm{IHH} \\
Q \\
\text { cell } 4\end{array}$ & $\begin{array}{c}\text { IHV } \\
\text { I } \\
\text { cell } 4\end{array}$ & $\begin{array}{c}\text { IHV } \\
Q \\
\text { cell } 4\end{array}$ & & $\begin{array}{c}\mathrm{IHH} \\
I \\
\text { cell } N\end{array}$ & $\begin{array}{c}\mathrm{IHH} \\
\mathrm{Q} \\
\text { cell } \mathrm{N}\end{array}$ & $\begin{array}{c}\text { IHV } \\
1 \\
\text { cell } N\end{array}$ & $\begin{array}{c}\text { IHV } \\
Q \\
\text { cell } N\end{array}$ & $\begin{array}{l}1 \\
y\end{array}$ \\
\hline \multirow{2}{*}{ 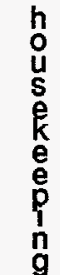 } & $\begin{array}{c}\text { JWV } \\
1 \\
\text { cell } 1\end{array}$ & $\begin{array}{c}\text { JVV } \\
Q \\
\text { cell } 1\end{array}$ & $\begin{array}{c}\text { JVH } \\
1 \\
\text { cell } 1\end{array}$ & $\begin{array}{c}\text { JVH } \\
Q \\
\text { cell } 1\end{array}$ & $\begin{array}{c}\text { JVV } \\
\text { I } \\
\text { cell } 3\end{array}$ & $\begin{array}{c}\text { JW } \\
Q \\
\text { cell } 3\end{array}$ & $\begin{array}{c}\text { JVH } \\
1 \\
\text { cell } 3\end{array}$ & $\begin{array}{c}\text { JVH } \\
\text { Q } \\
\text { cell } 3\end{array}$ & \multirow{2}{*}{$\bullet \bullet \bullet$} & $\begin{array}{c}\mathrm{JW} \\
1 \\
\text { cell N- }\end{array}$ & $\begin{array}{c}\mathrm{JVV} \\
\mathrm{Q} \\
\text { cell } \mathrm{N}-1\end{array}$ & $\begin{array}{c}J \mathrm{NH} \\
\quad 1 \\
\text { cell } N-1\end{array}$ & $\mid \begin{array}{c}J V H \\
Q \\
\text { cell } N-1\end{array}$ & $\mid \begin{array}{l}\mathbf{p} \\
\mathbf{a} \\
\mathbf{r}\end{array}$ \\
\hline & $\begin{array}{c}\text { JVV } \\
1 \\
\text { cell } 2\end{array}$ & $\begin{array}{c}\text { JVV } \\
Q \\
\text { cell } 2\end{array}$ & $\begin{array}{c}\text { JVH } \\
\text { I } \\
\text { cell } 2\end{array}$ & $\begin{array}{c}\text { JVH } \\
Q \\
\text { cell } 2\end{array}$ & $\begin{array}{c}\text { JVV } \\
1 \\
\text { cell } 4\end{array}$ & $\begin{array}{c}\text { JVV } \\
\text { Q } \\
\text { cell } 4\end{array}$ & $\begin{array}{c}\text { JVH } \\
1 \\
\text { cell } 4\end{array}$ & $\begin{array}{c}\text { JVH } \\
\text { Q } \\
\text { cell } 4\end{array}$ & & $\begin{array}{c}\text { JW } \\
1 \\
\text { cell } N\end{array}$ & $\begin{array}{l}\text { JWV } \\
Q \\
\text { cell N }\end{array}$ & $\begin{array}{c}\mathrm{JVH} \\
I \\
\text { cell } \mathrm{N}\end{array}$ & $\begin{array}{c}\text { JVH } \\
Q \\
\text { cell N }\end{array}$ & $\begin{array}{l}t \\
y\end{array}$ \\
\hline
\end{tabular}

Figure 2: Four sequential "raw" data planes when the radar is operating in monostatic band and polarization agile mode. The housekeeping (header) block is 128 bytes, the data block is 4096 bytes, and the parity block is 2 bytes. Each data cell is labeled by band (in UK-terminology) and polarization, complex part, and cell number. For example, "IHH" is I-band, H-transmit, and H-receive. The number of range cells, N, is 1024. Each data plane is to be read top to down, and left to right. Each small data cell represents one byte. 


\section{PRF Count 10701657 with -1 Shift}
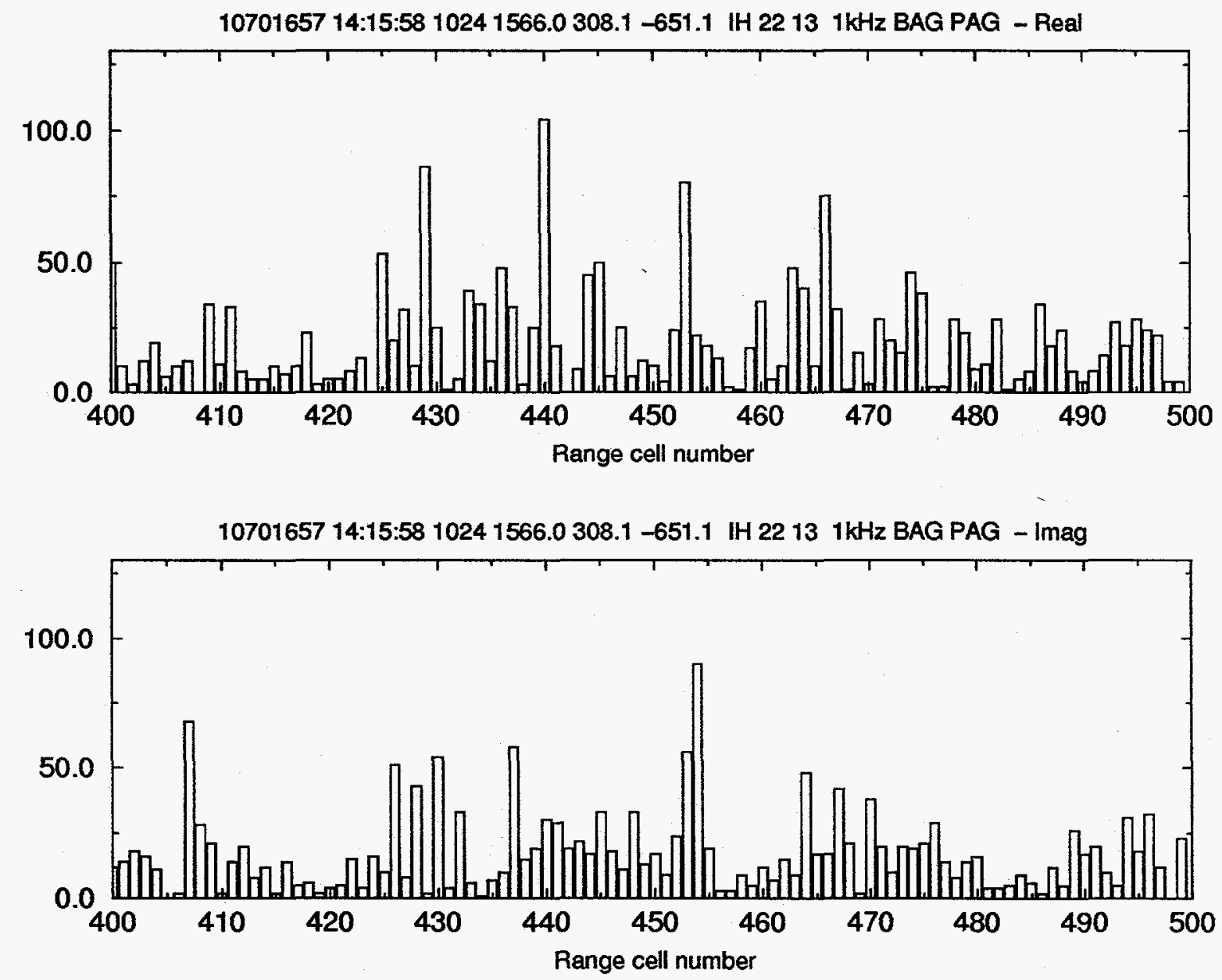

Figure 3: -1 (left) shift of the data shown in Figure 1. The ghosting has been eliminated. 


\section{PRF Count 10701657 with +1 Shift}
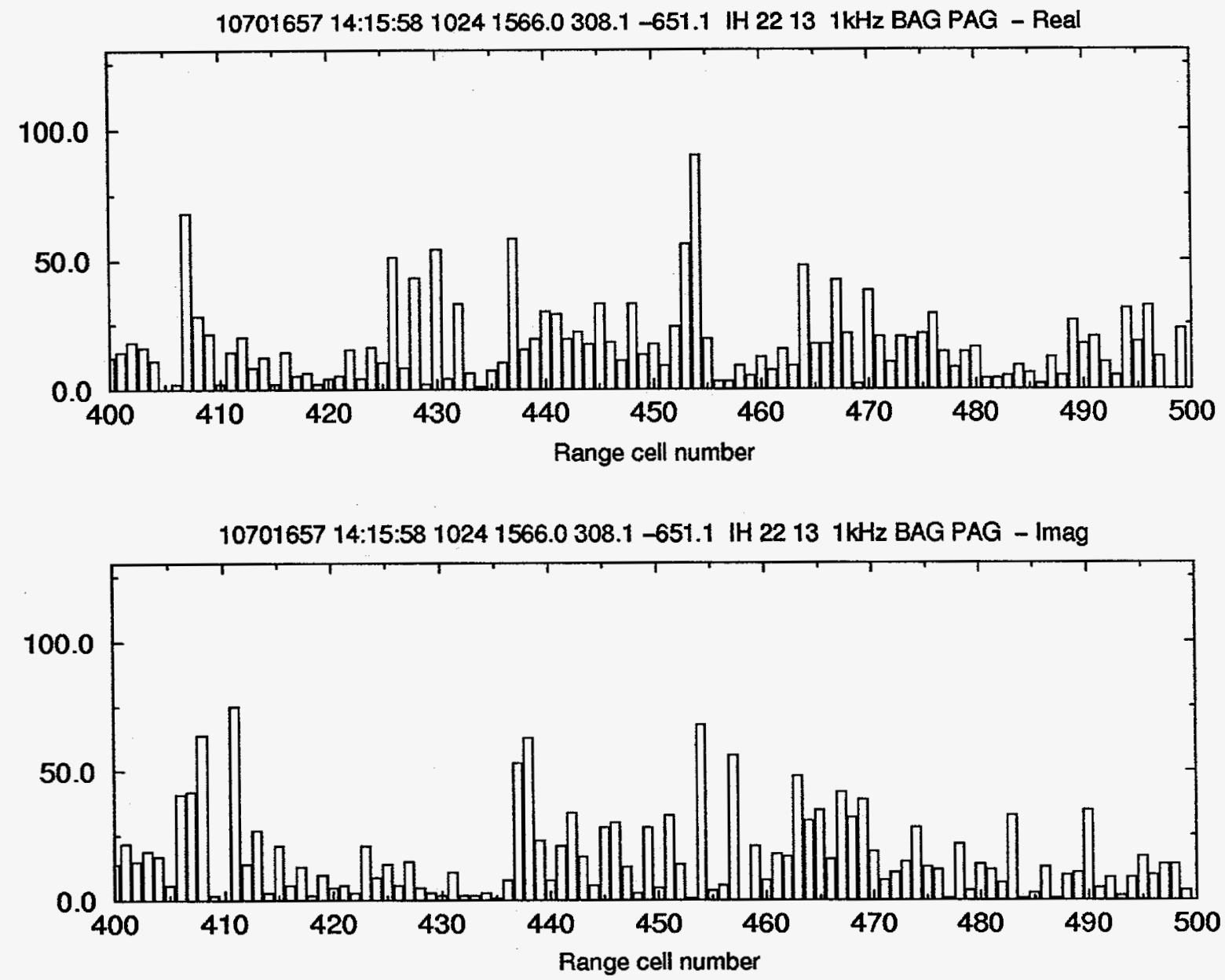

Figure 4: +1 (right) shift of the data shown in Figure 1. The ghosting has been eliminated. 
Doppler Profiles

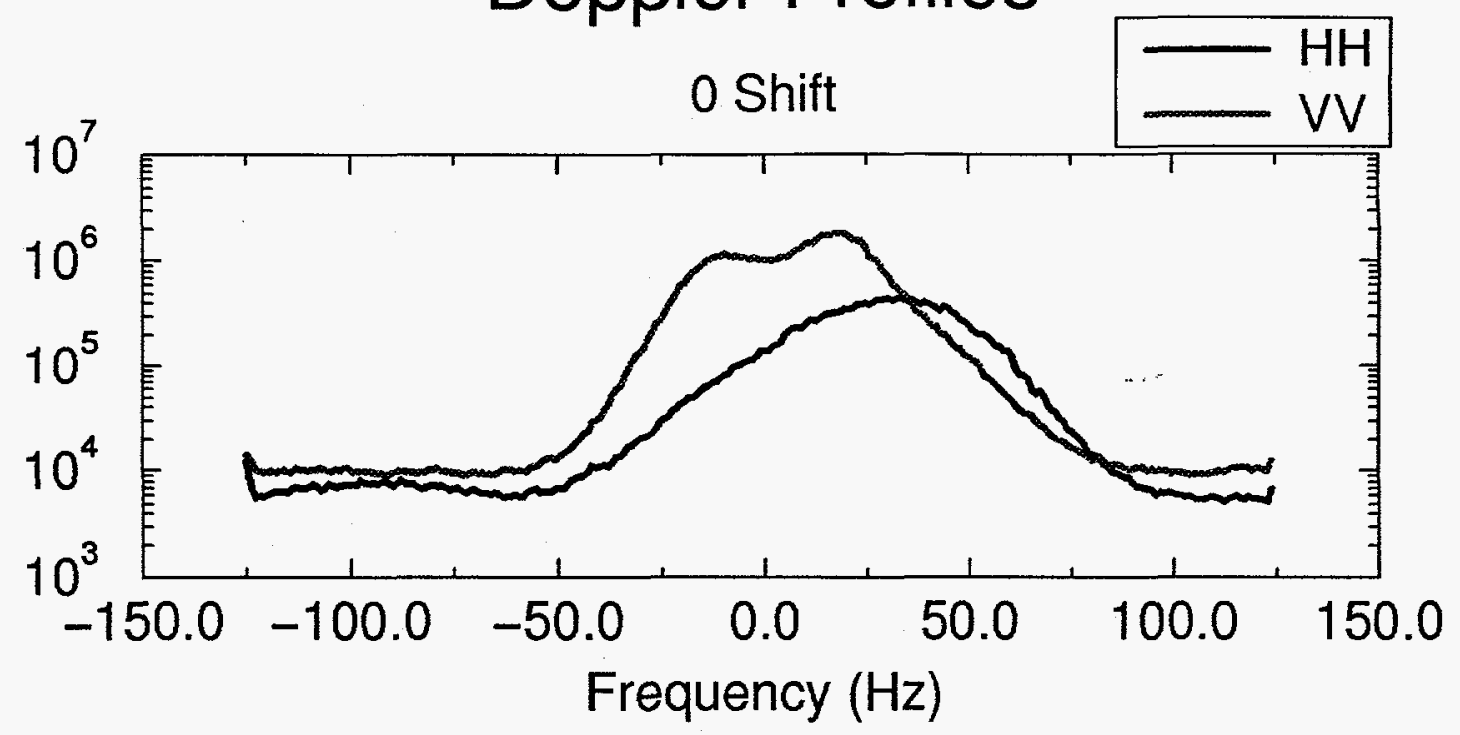

-1 Shift

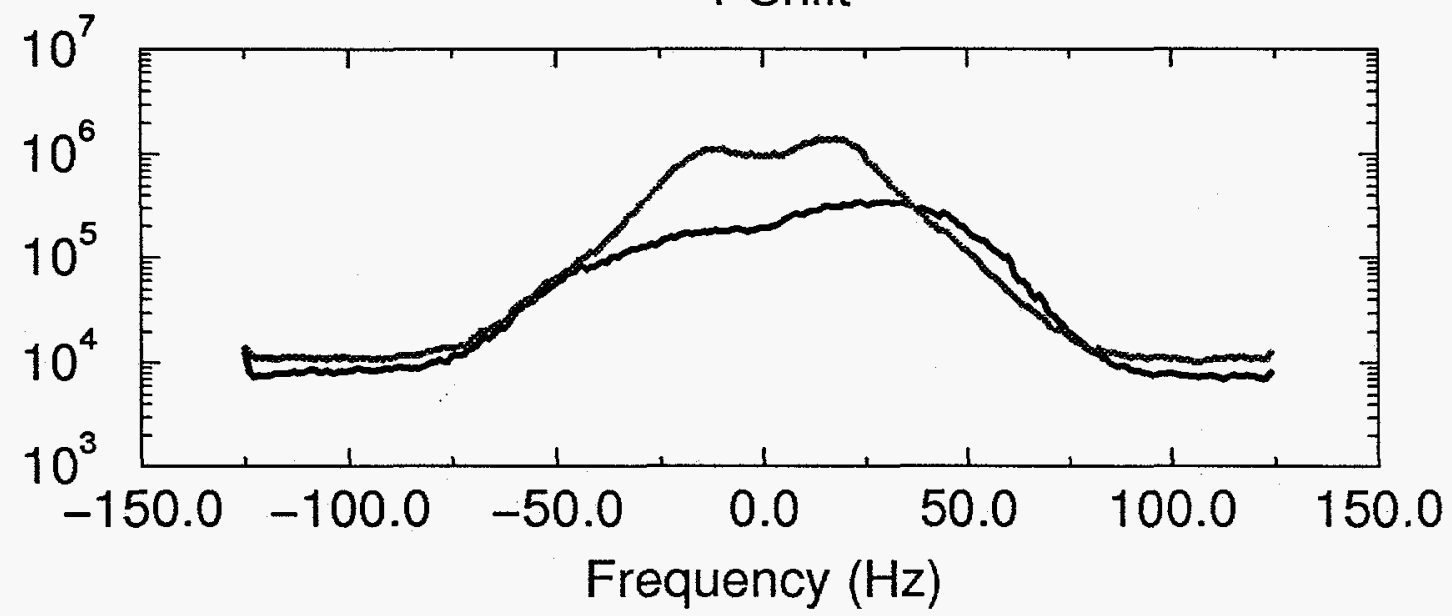

+1 Shift

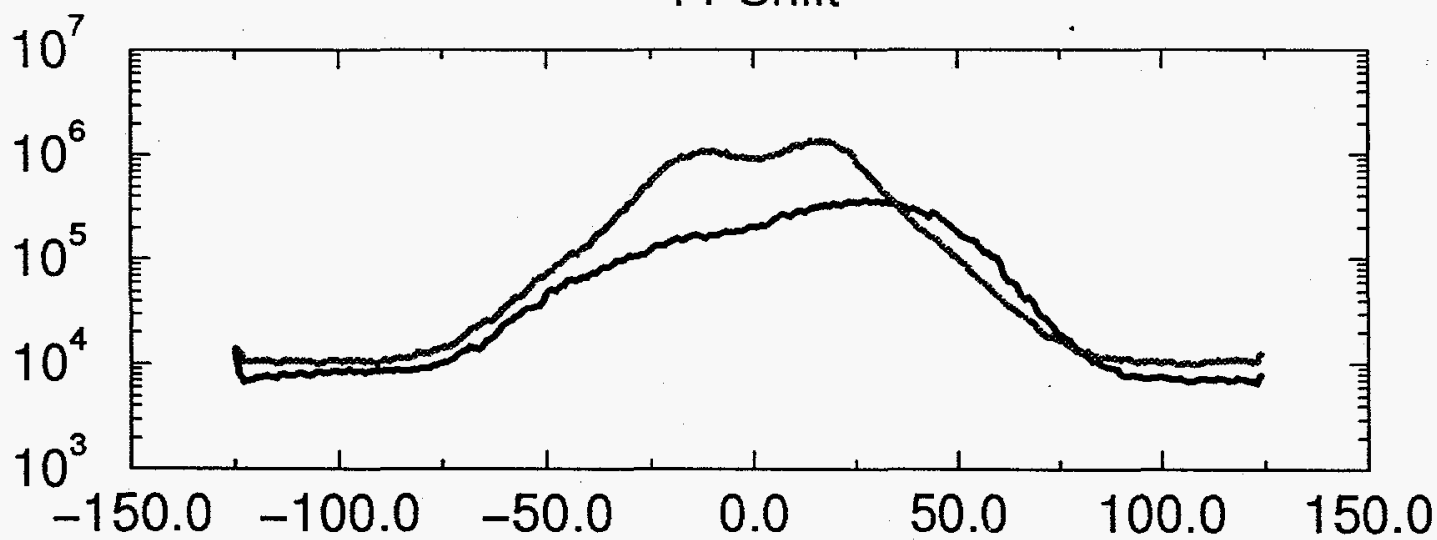

Frequency $(\mathrm{Hz})$
Figure 5: Doppler profiles from spectra estimated over 5 seconds. Sifts in the data do not appear to affect the profiles. 